\title{
A RELIABLE METHOD FOR OBTAINING HIGH-RESO- LUTION BANDED CHROMOSOME PREPARATIONS FROM CHORIONIC VILLUS SAMPLES
}

\author{
Han-Xiang Deng, ${ }^{1,2}$ Lu-Yun LI, ${ }^{1}$ Jia-Hui XIA, ${ }^{1}$ and Norio NiIKAWA ${ }^{2}$ \\ 'Department of Medical Genetics, Hunan Medical University, \\ Changsha, Hunan, People's Republic of China \\ ${ }^{2}$ Department of Human Genetics, Nagasaki University School of Medicine, \\ Sakamoto-machi 12-14, Nagasaki 852, Japan
}

\begin{abstract}
Summary A reliable method for obtaining high-resolution banded chromosome preparations from chorionic villus samples (CVS) is described, in which a synchronization cell-culture technique with the use of thymidine is introduced. After culturing a suspension of chorionic villus cells in a medium supplemented with $0.3 \mathrm{mg} / \mathrm{ml}$ thymidine for 13-17 hr, cells were washed twice, and recultured for further $8 \mathrm{hr}$. The cells were then treated with $10 \mu \mathrm{g} / \mathrm{ml}$ ethidium bromide or $1 \mu \mathrm{g} / \mathrm{ml}$ actinomycin D for $1 \mathrm{hr}$ and subsequently with $0.01 \mu \mathrm{g} / \mathrm{ml}$ Colcemid for $30 \mathrm{~min}$. The average mitotic index obtained was more than 60 mitoses $/ \mathrm{mg} \mathrm{CVS}$, and more than $60 \%$ of mitoses proceeded to the prometaphase stage, the later prophase stage, or in between. The application of this method for prenatal diagnoses in five CVS in the first trimester pregnancies proved that it is a simple, practical and efficient prenatal diagnostic method.
\end{abstract}

Key Words synchronization cell-culture method, chorionic villi, highresolution chromosome banding technique, prenatal diagnosis

\section{INTRODUCTION}

A combination of chorionic villus sampling (CVS) with chromosome analysis allows prenatal diagnosis of chromosome abnormalities in the first trimester of pregnancy. Cytogenetic analysis on CVS has been performed with the use of either of the following two methods: the monolayer cell culture from which chromosome preparations are made (Niazi et al., 1981; Xia et al., 1984) and the direct method in which the preparation is obtained from short-term culture of minced CVS (Simoni et al., 1983). These techniques have both advantages and drawbacks.

Received October 9, 1989; revised version received December 28, 1989; Accepted December 29, 1989.

Request reprints to: Deng Han-Xiang, Department of Human Genetics, Nagasaki University School of Medicine, Sakamoto-machi 12-4, Nagasaki 852, Japan. 
Although the former method provides a higher mitotic index and high-resolution banding on chromosomes, the risk of maternal cell contamination is too high to be clinically acceptable for the purpose of an accurate prenatal diagnosis (Xia et al., 1984; Yu et al., 1986). In addition, a 6-day to 20-day-culture is necessary to obtain a sufficient number of mitotic cells. The latter method offers advantages of rapid results (24-72 hr after CVS) and a small risk of the maternal cell contamination (Simoni et al., 1983), while it is often difficult to obtain high-resolution banded chromosome preparations (Cheung et al., 1987), mainly because of a low mitotic index and the incontrollable cell cycle.

We report here a reliable method of short-term synchronization culture of a villus cell suspension with which satisfactorily quantitative and qualitative highresolution banded chromosome preparations are available.

\section{MATERIALS AND METHODS}

Chorionic villus samplings (CVS) were performed in pregnant women with a desire of induced abortion with transcervical aspiration of the villus using a catheter at 6-9 weeks of gestation. Among 186 samples experimented in this study, five were analyzed in detail. The method of culture and the procedures for chromosome preparations in the present study were as follows:

(1) Freshly obtained villi $(5-15 \mathrm{mg})$ were roughly minced to make a villus suspension, and the suspension was cultured in RPMI 1640 medium with $0.3 \mathrm{mg} / \mathrm{ml}$ thymidine and $50 \%$ new-born bovine serum at $37^{\circ} \mathrm{C}$ for $13-17 \mathrm{hr}$.

(2) After 13-17 hr, the cells were washed twice with prewarmed RPMI 1640 medium supplemented with $50 \%$ new-born bovine serum and then recultured with the medium for $8 \mathrm{hr}$.

(3) At harvest, cells were treated with either $10 \mu \mathrm{g} / \mathrm{ml}$ ethidium bromide (Ikeuchi and Sasaki, 1979) or $1 \mu \mathrm{g} / \mathrm{ml}$ actinomycin D (Yunis, 1981) for $1 \mathrm{hr}$.

(4) Cells were then treated with $0.01 \mu \mathrm{g} / \mathrm{ml}$ Colcemid for $30 \mathrm{~min}$ and transferred to a centrifuge tube which was then stood for about one min, and the supernatant was discarded.

(5) Cells were treated with a hypotonic solution containing $0.2 \%$ sodium citrate and $0.2 \%$ potassium chloride at $37^{\circ} \mathrm{C}$ for $15 \mathrm{~min}$.

(6) Cell fixation was performed with 1:3 acetic methanol three times each for 10 min and then with prewarmed $40 \%$ aqueous acetic acid at $37^{\circ} \mathrm{C}$ for $1 \mathrm{~min}$.

(7) A cell suspension was made with gentle adding of 1:5 acetic methanol.

(8) After centrifuging at 1,000 rpm for $5 \mathrm{~min}, 3-4$ drops of $1: 3$ acetic methanol was added and the cells were gently mixed.

(9) A drop of the cell suspension was flood onto a cooled, wet slide.

(10) The slide was heated at $75^{\circ} \mathrm{C}$ for $8-12 \mathrm{hr}$ and chromosomes were then banded with the standard GTG-banding technique. 


\section{RESULTS AND DISCUSSION}

The present method adopted (1) a synchronization cell-culture technique combined with the ethidium bromide or actinomycin $\mathrm{D}$ treatment to inhibit chromosome condensation, (2) a cell suspension culture, and (3) cell harvest procedures with a short treatment of Colcemid in low concentration. With this method, the cell cycle could well be under control, so that a relatively large number of mitotic cells were yielded with an average of more than 60 mitoses/mg CVS, ranging from 50 to 95 (Table 1): Moreover, $60-70 \%$ of the mitotic cells were at the prometaphase and the later prophase stages or in between (Figs. 1 and 2). However, when exposure time to Colcemid was elongated to $1 \mathrm{hr}$, most of the mitotic cells reached at the metaphase or the prometaphase stage. The application of an aging method for chromosome slides with heating at $75^{\circ} \mathrm{C}$ allowed to obtain very clearly GTGbanded chromosomes.

Although amniocentesis has generally been used since 1966 as a practical prenatal diagnostic technique (Steele and Breg, 1966), it can only be performed in the midtrimester of pregnancy. Couples asking for fetal diagnosis and those electing to terminate pregnancy frequently undergo serious psychological stresses. Induced abortion in the midtrimester may involve legal, religious and social problems. Moreover, the midtrimester induced abortion has a higher risk of inducing severe medical problems. For these reasons, the technique of CVS in the first trimester and further culture and karyotyping techniques were developed as an alternative method of prenatal diagnosis. The technique for chromosome analysis after a monolayer cell culture of CVS (Niazi et al., 1981; Xia et al., 1984) and that with the direct culture method (Simoni et al., 1983) were recently reported. However, these methods have either or both of the following drawbacks: highly frequent maternal (decidual) cell contamination even after careful dissections of chorionic villi (Xia et al., 1984; Yu et al., 1986) and the difficulty of obtaining high-resolution banded chromosome preparations, possibly leading to misdiagnosis or overlooking of fine chromosome-abnormalities. A more recent method described by Cheung

Table 1. Mitosis counts from five consecutive synchronized preparations.

\begin{tabular}{ccc}
\hline $\begin{array}{c}\text { Amount of } \\
\text { tissues } \\
\text { prepared } \\
\text { (mg) }\end{array}$ & $\begin{array}{c}\text { Number of } \\
\text { mitoses } \\
\text { obtained } \\
\text { (mitoses/mg } \\
\text { tissue) }\end{array}$ & $\begin{array}{c}\text { Number }(\%) \\
\text { of early } \\
\text { mitoses }\end{array}$ \\
\hline 8 & $539(67.4)$ & $357(67.5)$ \\
13 & $795(61.1)$ & $540(67.9)$ \\
10 & $615(61.5)$ & $375(61.0)$ \\
15 & $748(49.9)$ & $528(70.6)$ \\
5 & $476(95.2)$ & $257(60.3)$ \\
\hline
\end{tabular}




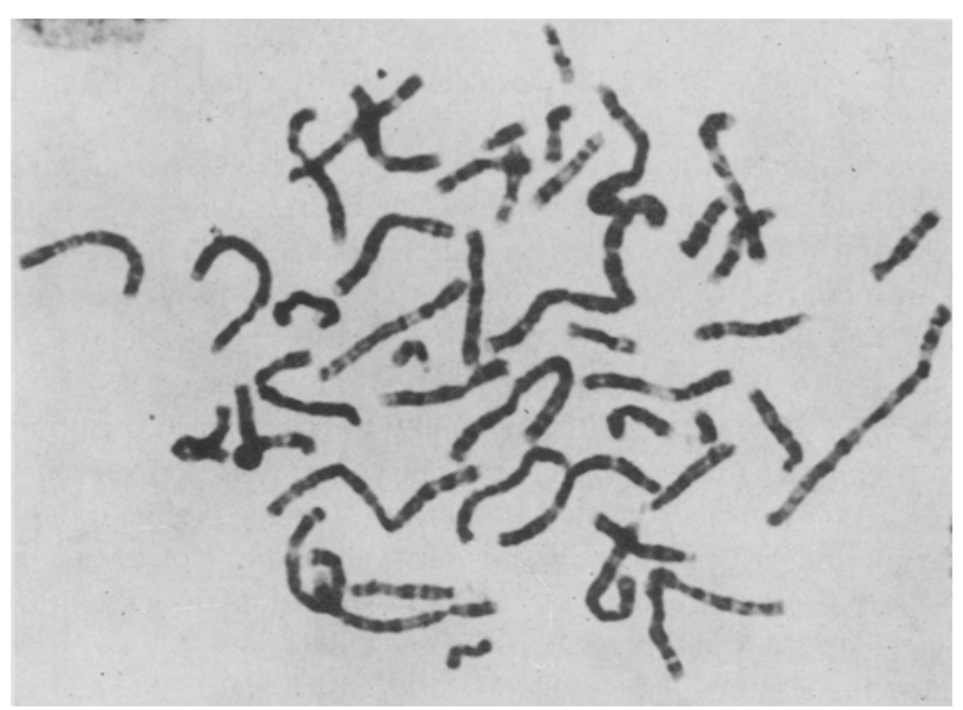

Fig. 1. High-resolution GTG-banded chromosome preparation at prometaphase stage.

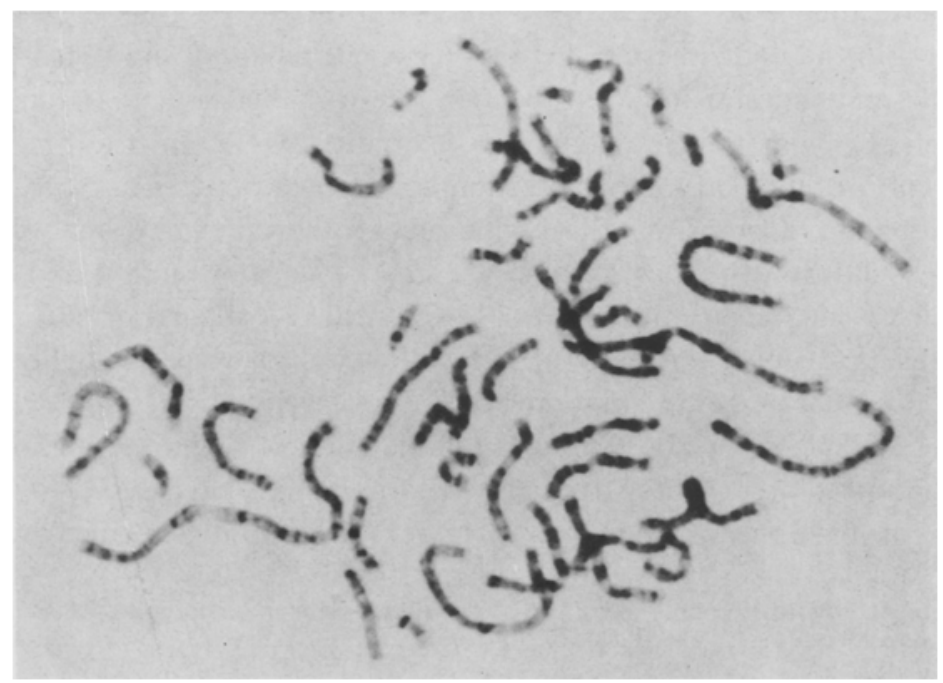

Fig. 2. High-resolution GTG-banded chromosome preparation at prometaphase to late prophase stage.

et al. (1987), in which they adopted a short-term culture of CVS and short-term treatment with a low concentration of Colcemid, allowed to avoid the maternal cell contamination and to obtain high-resolution banded chromosome preparations. However, this method seems still difficult to be used as a practical diagnostic method, because a mitosis rate was low and not stable, prometaphase cells being less than $20 \%$. 
Deng et al. (1990) recently demonstrated that in the condition of suspension cell culture, the villus cells were growth-dominant, whereas the growth of the decidual cells were suppressed and tended to become degenerated gradually from the second day of culture. Jensen et al. (1986) reported that in the condition of suspension culture, a tritium incorporation rate in the villus cells was increased as about 20 times as that in the decidual cells. These results suggest that the condition of suspension culture fits the physical growth of the villus cells, since in the normal physical condition a majority of the villus cells grow in a suspension condition surrounded by the maternal blood. This may be the reason why the risk of maternal cell contamination is high with the monolayer cell culture method.

The present method that empioys the cell synchronization technique and the suspension cell culture followed by treatment with a low concentration of Colcemid allowed successfully both to avoid the maternal cell contamination and to obtain prophase or prometaphase chromosomes with a high mitotic rate, indicating a stable, reliable and practical procedure. In our experience, among the procedures, the cell synchronization step is most critical to obtain a sufficient number of elongated chromosomes.

Acknowledgments We are indebted to Mr. Naoki Harada for providing photographs.

\section{REFERENCES}

Cheung, S.W., Crane, J.P., Kyine, M. and Cui, M.Y. 1987. Direct chromosome preparations from chorionic villi: a method for obtaining extended chromosomes and recognizing mosaicism confined to the placenta. Cytogenet. Cell Genet. 45: 118-120.

Deng, H-X., Li, L-Y. and Xia, J-H. 1990. A method of suspension cell culture and high-resolution chromosome banding technique for chorionic villi. J. Hered. Dis. (China) 7: 33-34.

Ikeuchi, T. and Sasaki, M. 1979. Accumulation of early mitotic cells in ethydium bromide-treated human Jymphocyte culture. Proc. Jpn. Acad. 55: 15-18.

Jensen, P.K.A., Hertz, J.M. and Therkelsen, A.J. 1986. Admixture of maternal metaphases in first trimester direct chromosome preparation? Prenat. Diag. 6: 383-385.

Niazi, M., Coleman, D.V. and Loeffler, F.E. 1981. Trophoblast sampling in early pregnancy. Culture of rapidly dividing cells from immature placental villi. Br. J. Obstet. Gynaecol. 88; 10811085.

Simoni, G., Brambati, B., Danesino, C., Rossella, F., Terzoli, G.L., Ferrari, M. and Fraccaro, M. 1983. Efficient direct chromosome analyses and enzyme determinations from chorionic villi samples in the first trimester of pregnancy. Hum. Genet. 63: 349-357.

Steele, M.W. and Breg, W.R., Jr. 1966. Chromosome analysis of human amniotic-fluid cells. Lancet i: $383-385$.

Xia, J-H., Li, L-Y., He, X-X., Xu, J., Xu, F-M. and Lu, H-L. 1984. A new method for chromosome diagnosis of the fetus in the first trimester of pregnancy. Hunan Med. Bull. (Changsha) 9: 11-14.

Yu, M-T., Yu, C-Y., Yu, C-X., Maidman, J. and Warburton, D. 1986. Improved methods of direct and cultured chromosome preparations from chorionic villus samples, Am. J. Hum. Genet. 38: 576-581.

Yunis, J.J. 1981. Mid-prophase human chromosomes. The attainment of 2,000 bands. Hum. Genet. 56: 293-298. 